\title{
Pendampingan Ujian Nasional Berbasis Komputer (UNBK) Mata Pelajaran Bahasa Inggris di SMA Pancasila Bengkulu
}

\author{
Elva Utami ${ }^{1 *}$, Yuneva $^{2}$ \\ ${ }^{1,2}$ Universitas Prof. Dr. Hazairin, SH., Jalan Jenderal Ahmad Yani No 1. Bengkulu \\ Email: Utamielva80@gmail.com*
}

\begin{abstract}
ABSTRAK
Pengabdian kepada masyarakat dilakukan melalui kegiatan yang berjudul Pendampingan Ujian Nasional Berbasis Komputer (UNBK) Mata Pelajaran Bahasa Inggris di SMA Pancasila Bengkulu. Kegiatan pengabdian masyarakat ini bertujuan untuk membantu siswa-siswi kelas XII dalam menghadapi Ujian Nasional Berbasis Komputer (UNBK) untuk mata pelajaran Bahasa Inggris dengan cara memberikan pengetahuan tentang simulasi UNBK, latihan-latihan soal serta tips dan trik dalam mengerjakan soal UNBK mata pelajaran Bahasa Inggris tersebut. Metode yang digunakan pada kegiatan pengabdian ini adalah metode ceramah dan diskusi pembahasan soal-soal UNBK Bahasa Inggris. Peserta yang menjadi target pelatihan ini adalah siswa-siswa kelas XII. Prosedur kegiatan ini adalah memberikan latihan-latihan soal kepada peserta, mendiskusikan dan bertanya jawab. Hasil kegiatan pengabdian ini menunjukkan bahwa ada perubahan sikap siswa dalam menghadapi UNBK, siswa lebih siap dan percaya diri dalam menghdapi UNBK pada mata pelajaran Bahasa Inggris tahun 2019. Dengan demikian, dapat dikatakan bahwa pendampingan Ujian Nasional Berbasis Komputer (UNBK) mata pelajaran Bahasa Inggris berhasil dan sukses.
\end{abstract}

Kata Kunci: Pendampingan; UNBK; Bahasa Inggris; SMA

\begin{abstract}
Community service is carried out through an activity entitled Assistance on Computer-Based National Examinations (UNBK) for English Subjects at SMA Pancasila Bengkulu. This community service activity was aimed to help students in class XII to face the Computer-Based National Examination (UNBK) for English subjects by providing knowledge about UNBK simulations, practice exercises and tips and tricks in working on UNBK English subjects. The method used in this dedication activity was the lecture and discussion of English UNBK questions. Participants who were the target of this training were students of class XII. The procedure of this activity was to give exercises to the participants, discussed and asked questions. The results of this service showed that there was a change in students' attitudes in dealing with UNBK; students were more prepared and confident in dealing with UNBK on English subjects in 2019. Thus, it can be said that the accompaniment of the Computer-Based National Examination (UNBK) of English subjects was successful.
\end{abstract}

Keyword: Assistance; UNBK; English; Senior High School 


\section{PENDAHULUAN}

Ujian Nasional Berbasis Komputer (UNBK) telah diselenggarakan oleh Pemerintah Republik Indonesia melalui Kementrian Pendidikan dan Kebudayaan (Kemendikbud) untuk jenjang SMP, SMK dan SMA sejak tahun 2015 (Anita, 2019). UNBK ini adalah salah satu faktor penentu kelulusan siswa (Ridha \& Istiqamah, 2013) dan juga merupakan sarana evaluasi terhadap siswa yang akan menyelesaikan pendidikan di sekolah untuk masuk ke Perguruan Tinggi. Evaluasi peserta didik, satuan pendidikan, dan program pendidikan dilakukan oleh lembaga mandiri secara berkala, menyeluruh, transparan, dan sistemik untuk menilai pencapaian standar nasional pendidikan (Pemerintah Indonesia, 2003). Oleh sebab itu sekolah merasa sangat perlu mempersiapkan siswa-siswinya dalam menghadapi UNBK ini.

Bahasa Inggris merupakan salah satu mata pelajaran yang masuk dalam Ujian Nasional Berbasis Komputer (UNBK) di SMA. Bagi sebagian besar siswa-siswi SMA menganggap Bahasa Inggris mata pelajaran yang sulit (Jana \& Rahmawan, 2019) karena Bahasa Inggris merupakan Bahasa kedua di negera kita dan sangat jarang digunakan dalam kehidupan sehari-hari sehingga banyak keterbatasan-keterbatasan yang dirasakan oleh kebanyakan siswa (Noor \& Aman, 2015). Oleh karenanya pihak sekolah harus mempersiapkan siswa-siswinya dengan sebaik mungkin untuk menghadapi UNBK Bahasa Inggris ini sehingga siswa-siswinya dapat mencapai standar kelulusan yang telah ditentukan oleh pemerintah yaitu 5,50. Penerapan standar dalam pendidikan ini tidak dimaksudkan untuk menyeragamkan pelaksanaan pendidikan, melainakn lebih bermaknasebagai standar pelayanan minimal (Lumapow, 2010).

Soal UNBK Bahasa Inggris terdiri atas 50 butir soal. Soal UNBK Bahasa Inggris ini meliputi soal listening sebanyak 15 butir soal dan 35 butir soal untuk soal reading dan grammar. Siswa harus menjawab 50 butir soal Bahasa Inggris ini dalam waktu 2 jam.

Berdasarkan hasil wawancara dengan guru-guru yang mengajar mata pelajaran Bahasa Inggris di SMA Pancasila Bengkulu, kebanyakan siswa mengalami kesulitan ketika berhadapan dengan soal-soal Bahasa Inggris. Pada sesi listening siswa mengalami kesulitan menangkap pesan yang disampaikan dikarenakan mereka harus mendengarkan dialog dan monolog yang dilakukan oleh native speaker. Sehingga mereka hanya menebak-nebak saja jawaban pada soal yang diberikan. Kemampuan listening merupakan hal yang sangat penting 
dalam pembelajaran Bahasa Inggris sehingga peserta diharapkan dapat memiliki kemampuan memahami teks-teks yang bersifat audio yang merupakan bagian komunikasi sehari-hari yang sangat dominan (Syafii \& Sugianto, 2017). Sedangkan pada sesi reading, keterbatasan kosakata (vocabulary) membuat mereka malas untuk memahami isi teks, ditambah lagi dengan teks reading yang panjang membuat mereka semakin bosan untuk membacanya akibatnya mereka menjawab dengan asal-asalan dan ini tentu saja berimbas dengan nilai yang UNBK yang mereka peroleh. Demikian juga dengan soal-soal grammar. Ketidakpahaman siswasiswa dengan kosakata dan soal grammar yang diberikan juga membuat mereka cenderung menebak saja jawaban dari setiap soal. Oleh karena itu, kegiatan pengabdian masyarakat Pendampingan Ujian Nasional Berbasis Komputer (UNBK) untuk mata pelajaran Bahasa Inggris ini sangat perlu dan urgen dilaksanakan sebagai solusi untuk membantu siswa-siswi dalam menghadapi UNBK Bahasa Inggris.

\section{METODE}

Kegiatan pengabdian masyarakat ini dilaksanakan selama 1 bulan. Artinya kegiatan pendampingan UNBK Bahasa Inggris ini dilakukan selama 4 kali pertemuan. Dimana dalam satu minggu dilakukan satu kali pertemuan. Satu kali pertemuan tatap muka berlangsung selama 90 menit. Sedangkan untuk masalah hari pelaksanaan tergantung pada kesepakatan jadwal antara Tim pengabdian dengan sekolah mitra yaitu hari Sabtu, Senin, Selasa dan Kamis, jam 10.00 - 11. 30 Wib bertempat diruang aula SMA Pancasila Bengkulu. Pertemuan pertama dilakukan pembahasan mengenai soal listening. Pertemuan kedua membahas tentang soal reading. Pertemuan ketiga membahas tentang soal grammar, sedangkan pada pertemuan keempat diberikan tips dan trik dalam menjawab soal UNBK Bahasa Inggris. Metode yang digunakan pada kegiatan pengabdian ini adalah metode ceramah, dan diskusi pembahasan soal-soal ujian nasional untuk mata pelajaran Bahasa Inggris.

Kegiatan pendampingan ini terbagi atas tiga kegiatan yaitu :

1. Tim pengabdian dari Prodi Pendidikan Bahasa Inggris Universitas Prof. Dr. Hazairin, SH memberi pemaparan singkat tentang UNBK. Tim Pengabdian juga menjelaskan mengenai simulasi tutorial login melalui media computer dengan memutarkan video tutorial simulasi UNBK yang dibuat oleh PUSPENDIK. 
2. Siswa mengerjakan soal UNBK untuk mata pelajaran Bahasa Inggris. Soal-soal UNBK mata pelajaran Bahasa Inggris tersebut diperoleh dari soal-soal UNBK tahuntahun sebelumnya. Pengerjaan soal-soal ini dilakukan secara offline atau menggunakan kertas dan pena. Kemudian mendiskusikannya dengan tim dosen pengabdian. Pemberian materi, latihan soal, dan evaluasi diharapkan dapat meningkatkan pemahaman pengetahuan, dan kemampuan bahasa inggris mitra (Wijayanti \& Miqawati, 2016).

3. Pemberian tips dan trik pengerjaan soal-soal UNBK Bahasa Inggris diberikan setelah siswa-melakukan simulasi pembahasan soal-soal. Pada bagian ini tim pengabdian menjelaskan tentang strategi siswa dalam memahami soal-soal UNBK sehingga mereka dengan mudah dapat menjawab soal-soal tersebut.

\section{HASIL DAN PEMBAHASAN}

Sebanyak 34 orang siswa kelas XII SMA Pencasila yang mengikuti kegiatan pendampingan UNBK mata pelajaran Bahasa Inggris ini. 15 orang siswa berasal dari jurusan IPA dan 19 orang siswa berasal dari jurusan IPS. Tetapi dalam pelaksanaan pendampingannya, 34 siswa yang berasal dari dua jurusan berbeda tersebut disatukan dalam satu ruangan besar yang biasa disebut aula.

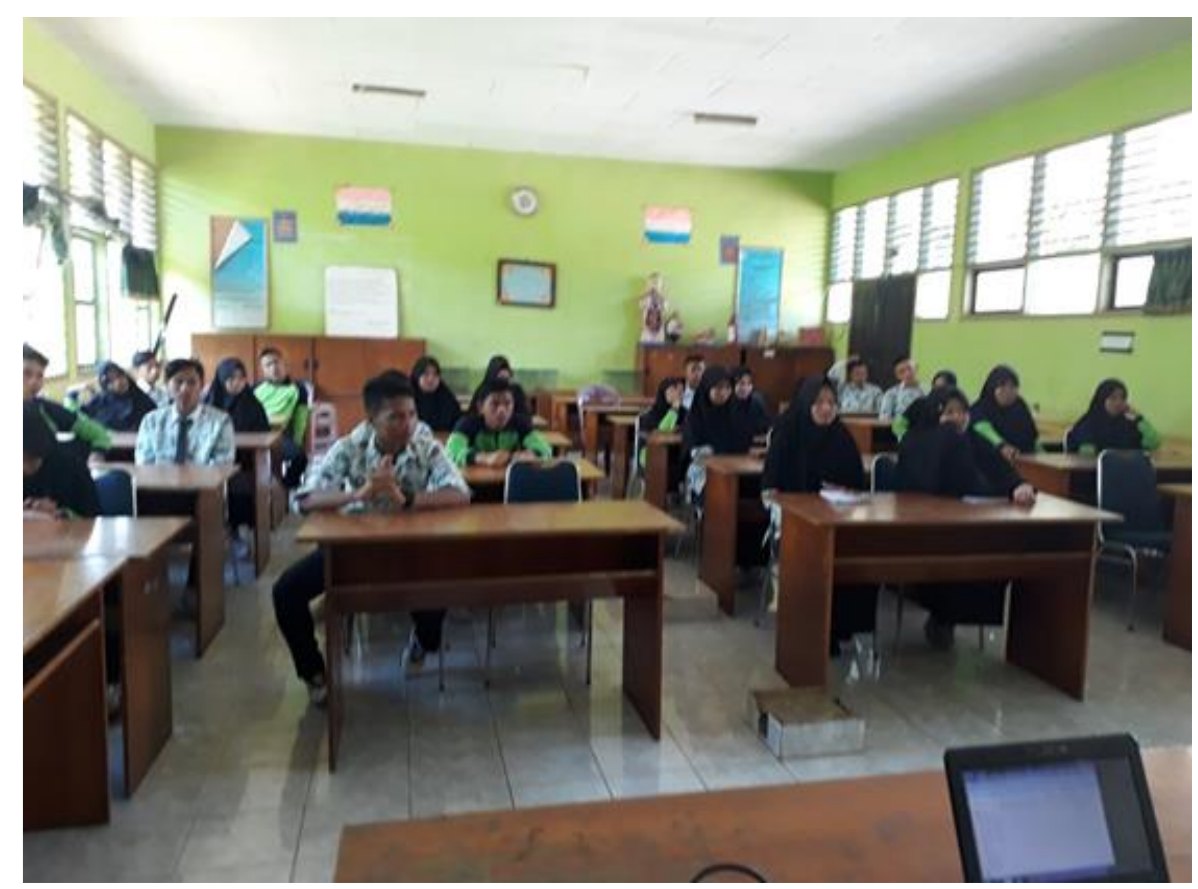

Gambar 1. Pemaparan tentang UNBK 
Pemaparan tentang UNBK dilakukan kepada para peserta pada pertemuan pertama..Tim pengabdian menyampaikan materi melalui penayangan video tutorial simulasi UNBK yang dibuat oleh Puspendik (Pusat Penilaian Pendidikan). Simulasi ini bertujuan untuk memberi pemahaman kepada siswa tentang tata cara melakukan login dan menjawab soal-soal UNBK. agar siswa terbiasa atau tidak kaget sewaktu melakukan UNBK yang sebenarmya. Pemaparan ini berlangsung selama 1 jam.

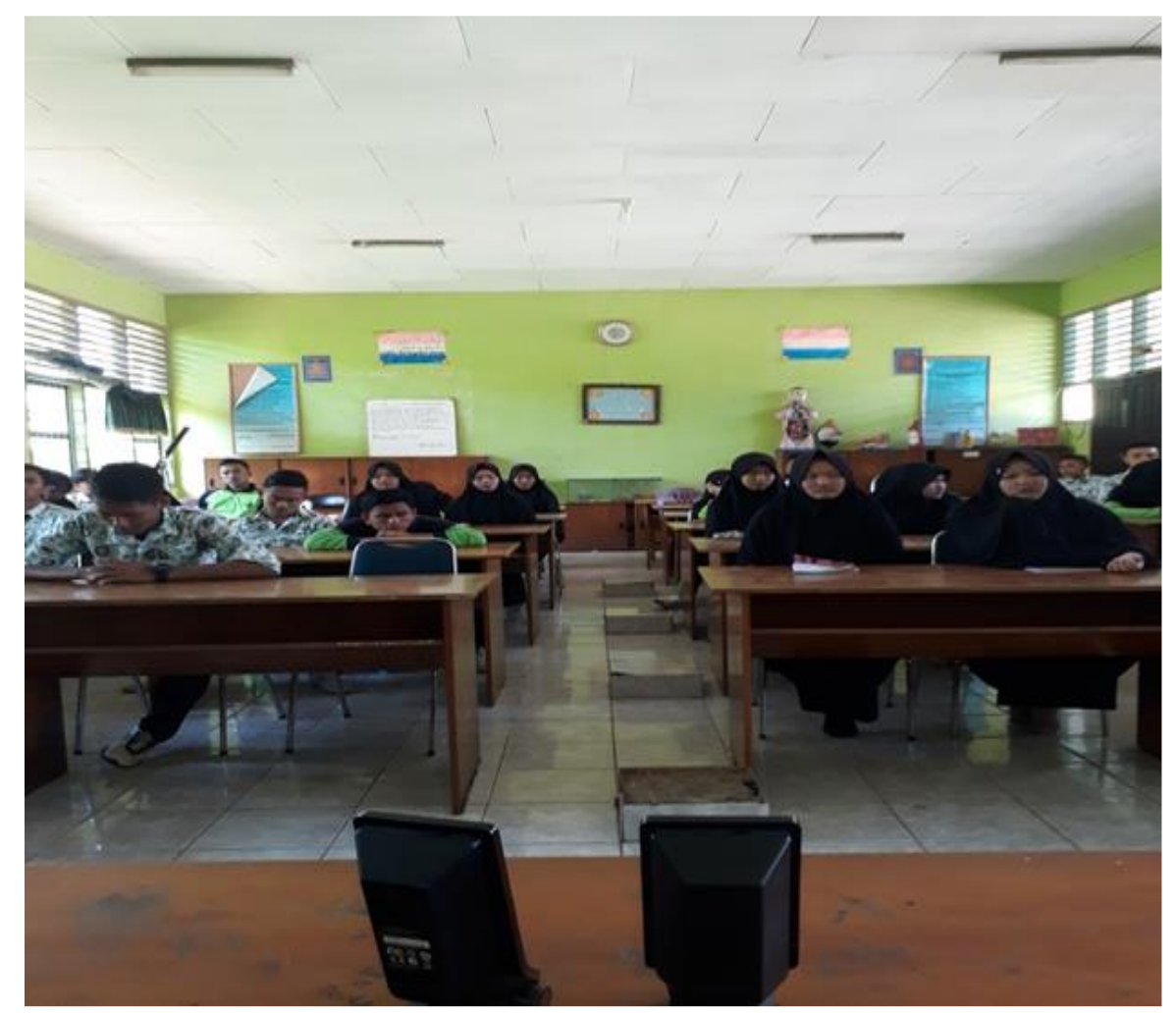

Gambar 2. Pemberian Materi Listening

Selanjutnya pada pertemuan kedua diberikan materi tentang listening. Ada empat bagian dalam skil listening ini yaitu dialogue, incomplete dialogue, monologue dengan gambar yang sudah ada dalam pilihan jawaban dan monologue tanpa gambar. Terdapat 15 soal pada skil listening ini. Setiap soalnya hanya diulang sebanyak 2 kali. Sehingga membutuhkan konsentrasi penuh untuk dapat menjawab semua soal tersebut. Pada bagian pertama siswa mendengarkan dialog singkat antara dua orang native speaker. Jumlah pertanyaan dari bagian pertama ini adalah 4 pertanyaan. Setiap pertanyaan terdiri atas satu dialog. Siswa harus memilih jawaban yang benar setelah dialog selesai. Pada bagian kedua siswa mendengarkan dialog yang belum lengkap (incomplete dialogue) yang diikuti oleh 
respon pembicaranya. Pada bagian ini siswa harus berkonsentrasi dengan respon akhir yang akan diucapkan oleh pembicara didalam dialog tersebut, karena siswa harus memilih respon yang benar pada setiap soalnya. Terdapat 3 pertanyaan untuk jenis soal incomplete dialogue ini. Selanjutnya adalah monolog dengan gambar. Siswa mendengarkan 4 monolog pada bagian ini. Setelah mendengarkan monolog siswa harus memilih gambar yang cocok seperti yang diceritakan pada monolog sebelumnya. Oleh sebab itu, siswa memerlukan tips dan trik agar dapat menjawab semua soal-soal tersebut dengan mudah dan cepat.

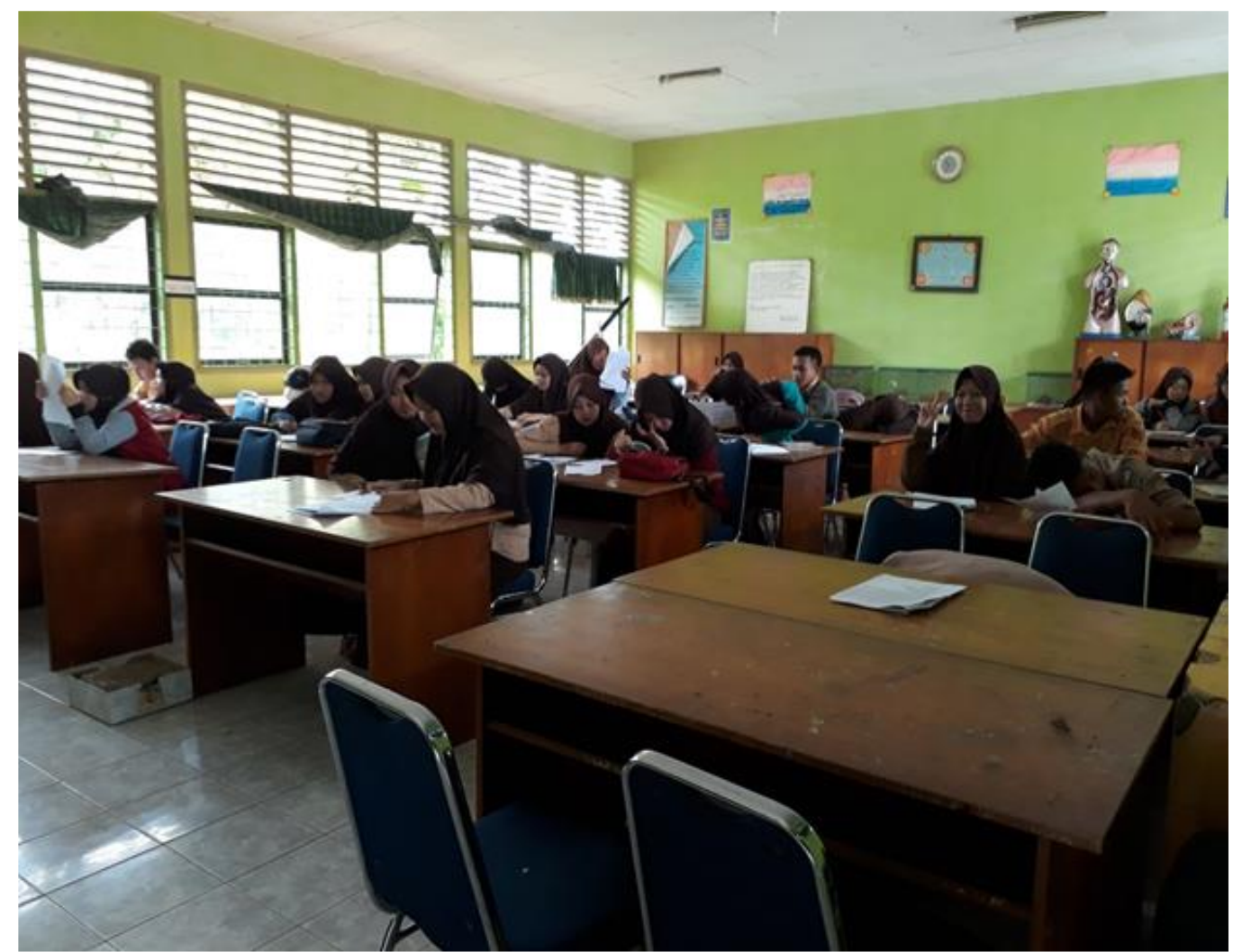

Gambar 3. Pemberian Materi Reading

Pada pertemuan ketiga tim pengabdi memberikan materi tentang reading. Materi reading pada UNBK Bahasa Inggris biasanya berisi tentang teks-teks yang sudah diajarkan dari kelas X SMA sampai dengan kelas XII SMA yang terdiri atas personal letter, announcement, narrative text, procedure text, hortatory exposition, dan descriptive text serta di tambah dengan soal-soal grammar. Berbagai macam jenis teks yang diberikan dalam soal reading ini akan menimbulkan berbagai macam kesulitan yang dihadapi oleh siswa. Misalnya bagaimana cara menentukan main idea sebuah text, mencari kata yang artinya sama (similar meaning), mencari kata ganti, atau menjawab pertanyaan-pertanyaan mengenai informasi detil (detail information) dalam sebuah teks. Oleh karena itu, pada skil reading juga 
diperlukan tips dan trik untuk menyiasatinya. Demikian juga untuk grammar, siswa akan menemukan soal-soal yang berkaitan dengan tenses. Oleh sebab itu siswa harus memahami tenses dengan baik sehimgga dapat meyelesaikan soal UNBK Bahasa Inggris dengan mudah. Pada skil grammar ini, juga diberikan tips dan trik untuk menyiasati agar siswa dapat menjawab soal dengan baik.

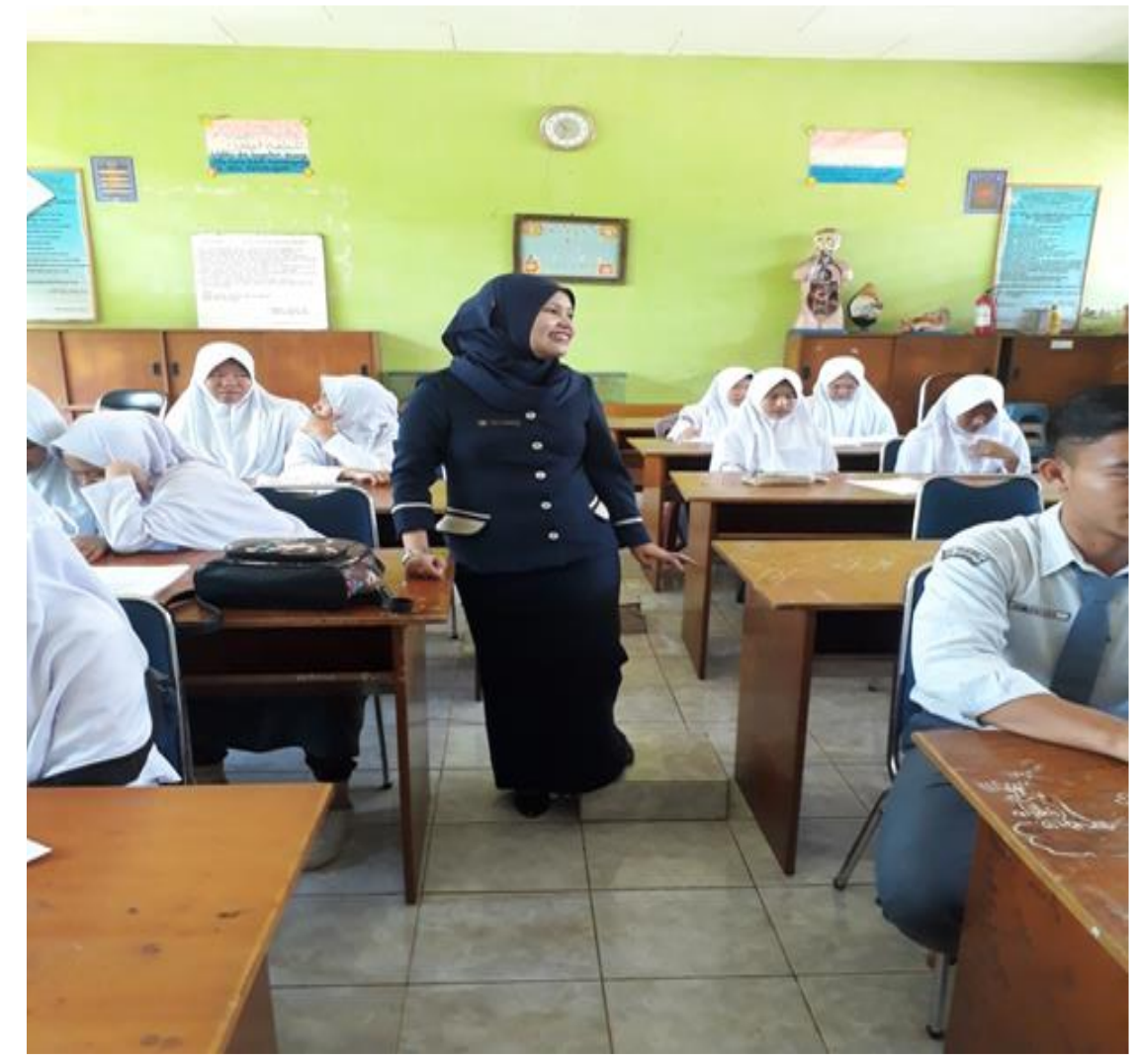

Gambar 4. Pemberian Materi Tips dan Trik

Pada pertemuan keempat siswa diberikan tips dan trik menjawab soal UNBK Bahasa Inggris dengan mudah, baik untuk skil listening maupun untuk skil reading dan grammar. Tim pengabdian menyampaikan materi tentang tips dan trik yang memudahkan siswa dalam menghadapi kesulitan-kesulitan yang siswa hadapi dalam soal UNBK Bahasa Inggris. Siswa juga diberi kebebasan bertanya atas semua kesulitan yang mereka hadapi. Mereka sangat bersemangat dan antusias sewaktu berdiskusi mengenai strategi untuk menyelesaikan soalsoal UNBK Bahasa Inggris yang mereka anggap sulit.

Kegiatan pendampingan UNBK mata pelajaran Bahasa Inggris ini mendapatkan sambutan positif dari siswa, terutama karena program ini sesuai dengan kebutuhan mereka. Bentuk sambutan positif tersebut antara lain terlihat dari partisipasi aktif dan baik dari siswa 
peserta pendampingan. Mereka termotivasi dan antusias selama mengikuti Pendampingan ini. Diskusi dan tanya jawab terjadi ketika ada bagian atau hal yang kurang dimengerti oleh mereka. Para siswa diberi kebebasan dalam bertanya agar peserta semakin memahami materi yang diberikan.

Dengan demikian dapat disimpulkan para siswa sangat antusias untuk meningkatkan kemampuan dan pemahaman mereka tentang mata pelajaran Bahasa Inggris. Antusiasme ini juga tercermin dari sikap mereka yang dengan senang hati mengerjakan soal-soal simulasi yang diberikan oleh tim pengabdian tanpa paksaan. Bahkan mereka berlomba-lomba untuk menyelesaikan soal-soal tersebut dengan cepat. Maka dapat disimpulkan bahwa pendampingan Ujian Nasional Berbasis Komputer (UNBK) mata pelajaran Bahasa Inggris berjalan sukses dan berhasil. Hal ini dapat dilihat dari perubahan tingkah laku dan sikap yang ditunjukan oleh oleh para siswa dalam menghadapi dan menyelesaikan soal-soal UNBK Bahasa Inggris.

\section{SIMPULAN}

Pendampingan Ujian Nasional Berbasis Komputer (UNBK) mata pelajaran Bahasa Inggris di SMA Pancasila ini dapat disimpulkan berjalan dengan sukses dan berhasil. Hal ini dapat dilihat dari adanya perubahan tingkah laku dan sikap siswa dalam menghadapi UNBK. Dari yang tidak percaya diri, kurang aktif, tidak antusias dan cuek menjadi lebih percaya diri, lebih aktif, lebih antusias dan lebih peduli terhadap UNBK yang akan mereka hadapi. Selama kegiatan pendampingan UNBK ini berlangsung siswa mau berinteraksi dan berkolaborasi dengan tim pengabdi sehingga terjadi perubahan sikap siswa dalam menyelesaikan soal-soal UNBK. Disamping itu siswa juga merasa lebih siap dalam menghadapi UNBK 2019 pada mata pelajaran Bahasa Inggris karena sudah dibekali dengan tips dan trik penyelesaian soalsoal UNBK yang akan mereka hadapi pada tahun 2019.

\section{UCAPAN TERIMAKASIH}

Terimakasih kepada Universitas Prof. Dr. Hazairin, SH Bengkulu yang telah mendukung dan mendanai Program Pengabdian Kepada Masyarakat ini. 


\section{DAFTAR PUSTAKA}

Anita, F., Kusumaningsih, C., Syahadati, E., \& Ramadhiyanti, Y. (2019). Pendampingan Penyelesaian Soal Ujian Nasional Berbasis Komputer ( Unbk ) Pada Mata Pelajaran Bahasa Inggris Di Sma Pancasila. Gervasi: Jurnal Pengabdian Kepada Masyarakat, $3(1), 12-23$.

Jana, P., \& Rahmawan, A. D. (2019). Pendampingan Persiapan Ujian Nasional Berbasis Komputer Pada Siswa Sma Muhammadiyah 3 Yogyakarta (Computer Based National Exam Guidance For The Students Of Muhammadiyah 3 Senior High School Yogyakarta. Jurnal Berdaya Mandiri, 1(1), 84-89.

Lumapow, H. (2010). Identifikasi Materi Sulit Ujian Nasional Bahasa Inggris Pada Siswa Jurusan Bahasa. Jurnal Kependidikan, 42(1), 61-75.

Noor, W. N., \& Aman. (2015). Evaluasi Penyelenggaraan Latihan Ujian Nasional Bahasa Inggris Sma Swasta Ex-Rsbi. Jurnal Penelitian Dan Evaluasi Pendidikan, 19(2), 217229.

Pemerintah Indonesia. (2003). Undang-Undang No.20 Tahun 2003 Tentang Sistem Pendidikan Nasional. Republik Indonesia.

Ridha, A. M., \& Istiqamah. (2013). Pelatihan Penguasaan Soal Un Mata Pelajaran Bahasa Indonesia Pada Siswa Kelas Xii Sman 2 Banjarmasin Indonesian Language Subject Practice Mastery Training For Class Xii Students Of Sman 2 Banjarmasin. Jurnal Ilmiah Pengabdian Masyarakat Pengabdianmu, 4(1), 15-18. Retrieved From Https://Doi.Org/10.33084/Pengabdianmu.V4i1.551.\%0a

Syafii, L., \& Sugianto, A. (2017). Pelatihan Bahasa Inggris Berekuivalensi Toefl Bagi Dosen Universitas Muhammadiyah Ponorogo. Jurnal Pengabdian Kepada Masyarakat Adimas, 1(1), 25-30.

Wijayanti, F., \& Miqawati, A. H. (2016). Pelatihan Test Of English As A Foreign Language ( Toefl ) Ekuivalen Anggota Ukm E-Club Politeknik Negeri Jember. Seminar Hasil Penelitian Dan Pengabdian Masyarakat, 177-180. 